Keywords: ovarian cancer; high grade serous carcinoma; biopsy; image-guided; methanol fixation; next-generation sequencing; tagged-amplicon sequencing

\title{
Safety and utility of image-guided research biopsies in relapsed high-grade serous ovarian carcinoma-experience of the BriTROC consortium
}

T Goranova ${ }^{1}$, D Ennis ${ }^{2}$, A M Piskorz , G Macintyre ${ }^{1}$, L A Lewsley ${ }^{3}$, J Stobo ${ }^{3}$, C Wilson ${ }^{3}$, D Kay ${ }^{4}$, R M Glasspool ${ }^{5}$, M Lockley 6,7, E Brockbank $^{6}$, A Montes $^{8}$, A Walther $^{9}$, S Sundar $^{10}, \mathrm{R}$ Edmondson ${ }^{11}$, G D Hall ${ }^{12}$, A Clamp $^{13}$, $\mathrm{C}$ Gourley $^{14}, \mathrm{M} \mathrm{Hall}^{15}, \mathrm{C}$ Fotopoulou ${ }^{16}, \mathrm{H} \mathrm{Gabra}^{16}$, S Freeman ${ }^{17}$, L Moore ${ }^{17}$, M Jimenez-Linan ${ }^{17}, \mathrm{~J} \mathrm{Paul}^{3}$, J D Brenton ${ }^{\star 1,17}$ and I A McNeish ${ }^{*, 2,5}$ on behalf of the BriTROC investigators ${ }^{18}$

${ }^{1}$ Cancer Research UK Cambridge Institute, Cambridge CB2 ORE, UK; ${ }^{2}$ Institute of Cancer Sciences, University of Glasgow, G61 1QH, UK; ${ }^{3}$ Cancer Research UK Clinical Trials Unit, Glasgow G12 OYN, UK; ${ }^{4}$ Department of Radiology, Gartnavel General Hospital, Glasgow G12 OYN, UK; ${ }^{5}$ Beatson West of Scotland Cancer Centre, Glasgow G12 OYN, UK; ${ }^{6}$ Barts Cancer Institute, London EC1M 6BQ, UK; ${ }^{7}$ University College Hospital, London WC1E 6BD, UK; ${ }^{8}$ Guy's Hospital, London SE1 9RT, UK; ${ }^{9}$ Bristol Haematology and Oncology Centre, Bristol BS2 8ED, UK; ${ }^{10}$ City Hospital, Birmingham B18 7QH, UK; ${ }^{11}$ St Mary's Hospital, Manchester M13 9WL, UK; ${ }^{12}$ St James Hospital, Leeds LS9 7TF, UK; ${ }^{13}$ The Christie Hospital, Manchester M20 4BX, UK; ${ }^{14}$ Edinburgh Cancer Research Centre, Edinburgh EH4 2XR, UK; ${ }^{15}$ Mount Vernon Cancer Centre, Northwood HA6 2RN, UK; ${ }^{16}$ Imperial College, London W12 OHS, UK and ${ }^{17}$ Addenbrooke's Hospital, Cambridge CB2 0QQ, UK

Background: Investigating tumour evolution and acquired chemotherapy resistance requires analysis of sequential tumour material. We describe the feasibility of obtaining research biopsies in women with relapsed ovarian high-grade serous carcinoma (HGSC).

Methods: Women with relapsed ovarian HGSC underwent either image-guided biopsy or intra-operative biopsy during secondary debulking, and samples were fixed in methanol-based fixative. Tagged-amplicon sequencing was performed on biopsy DNA.

Results: We screened 519 patients in order to enrol 220. Two hundred and two patients underwent successful biopsy, 118 of which were image-guided. There were 22 study-related adverse events (AE) in the image-guided biopsies, all grades 1 and 2; pain was the commonest AE. There were pre-specified significant AE in 3/118 biopsies (2.5\%). 87\% biopsies were fit-for-purpose for genomic analyses. Median DNA yield was $2.87 \mu \mathrm{g}$, and was higher in biopsies utilising $14 \mathrm{G}$ or $16 \mathrm{G}$ needles compared to $18 \mathrm{G}$. TP53 mutations were identified in $94.4 \%$ patients.

Conclusions: Obtaining tumour biopsies for research in relapsed HGSC is safe and feasible. Adverse events are rare. The large majority of biopsies yield sufficient DNA for genomic analyses-we recommend use of larger gauge needles and methanol fixation for such biopsies, as DNA yields are higher but with no increase in AEs.

*Correspondence: Dr JD Brenton; E-mail: james.brenton@cruk.cam.ac.uk or Professor IA McNeish; E-mail: iain.mcneish@glasgow.ac.uk

${ }^{18} \mathrm{~A}$ full list of BriTROC investigators is supplied in Supplementary Material. 
The commonest subtype of ovarian cancer, high-grade serous carcinoma (HGSC), accounts for $\sim 70 \%$ all cases, and $80 \%$ of deaths. Genomically, it is defined by near-universal TP53 mutation (Ahmed et al, 2010; Köbel et al, 2016), widespread copy number alterations (Gorringe et al, 2010; TCGA, 2011) and loss of gene function through complex structural rearrangements (Patch et al, 2015).

HGSC is initially sensitive to platinum-based chemotherapy but relapse occurs very frequently, with progressive development of platinum resistance, resulting in poor long-term survival (Mackay et al, 2010; Oza et al, 2015). Spatial and temporal heterogeneity have been frequently observed in HGSC, and low-frequency subclonal populations, which are present at the time of diagnosis, can undergo expansion during chemotherapy to become the predominant resistant population (Forshew et al, 2012; Schwarz et al, 2015). In addition, secondary or revertant mutations in $B R C A 1$ and BRCA2 may provide alternative mechanisms of abrogating platinum sensitivity (Edwards et al, 2008; Sakai et al, 2008; Patch et al, 2015).

Establishing accurate estimates of the prevalence of temporal heterogeneity and divergent evolution in HGSC will require sequential collection of tumour material at multiple time points during throughout course of the patient's disease, especially at relapse and progression. We and others have already demonstrated that image-guided biopsies can be obtained in patients with ovarian cancer (Spencer et al, 2006; Griffin et al, 2009; Swisher et al, 2017), whilst many early phase clinical trials now include translational research biopsies to investigate pharmacodynamic biomarkers. However, there is widespread variation in the reporting of outcomes of biopsy-driven studies (Freeman et al, 2013) and few data on the utility of these biopsies for complex genomic studies.

We have established BriTROC, a UK-based ovarian cancer consortium, which is investigating the acquisition of resistance in women with HGSC by focussing on the collection of sequential tumour biopsies, ctDNA and ascites from women with relapsed HGSC. We present here the interim data from the BriTROC-1 study in order to demonstrate the safety and feasibility of acquiring tumour biopsies in relapsed ovarian cancer across multiple academic centres. The secondary aim is to report the utility of methanol-fixed biopsies for next-generation sequencing analyses (Piskorz et al, 2016).

\section{PATIENTS AND METHODS}

Study conduct. The BriTROC-1 study was funded by Ovarian Cancer Action and sponsored by NHS Greater Glasgow and Clyde. A Trial Management Group (TMG, see Supplementary Material 1) designed and ran the study. Ethics/IRB approval was given by Cambridge Central Research Ethics Committee (Reference 12/EE/ 0349). The primary objective was to demonstrate the safety and feasibility of acquiring tumour biopsies from women with relapsed ovarian cancer in multiple centres. The secondary endpoints were to examine genomic alterations in relapsed ovarian HGSC. All patients provided written informed consent-this consent included specific consent to biopsy, use of biopsy material (and ascites if present) for genomic studies and testing of germline DNA for BRCA1/2 mutations. In addition, patients could optionally consent to a second biopsy upon disease progression and to be informed of germline BRCA1/2 analysis results. A copy of the patient consent form is included in Supplementary Material 7.

Significant complications were continuously monitored during the study. These were defined as grade $\geqslant 2$ events related to imageguided biopsy, specifically pain, haemorrhage, wound infection and peritoneal infection. The monitoring process used a one-sided (upward) CUSUM chart (Lerch et al, 2007) both study-wide and for individual sites. CUSUM control limits were set using an acceptable significant complication rate of $<5 \%$, an unacceptable rate of $>10 \%$, a power of $88 \%$ and a significance level of $10 \%$. If an individual site breached CUSUM control limits, that site was suspended pending detailed TMG review. If the whole study breached CUSUM control limits, recruitment was suspended to allow thorough review.

Patients. The study enrolled patients with recurrent ovarian highgrade serous or grade 3 endometrioid carcinoma who had relapsed following at least one line of platinum-based chemotherapy. Other histological subtypes were only allowed in patients with known deleterious germline BRCA1 or BRCA2 mutations. All patients had to have disease amenable either to image-guided or other interventional (e.g., endoscopy, bronchoscopy) biopsy, or secondary debulking surgery. Samples obtained at secondary debulking or other interventions were jointly classified as 'surgical' biopsies. Access to archival diagnostic formalin-fixed was also required, as well as snap frozen tumour material if available. Overall survival was calculated from the date of enrolment to the date of death or the last clinical assessment, with data cutoff at 1 December 2016. Full inclusion and exclusion criteria are listed in Supplementary Material 2.

Patients underwent biopsy (at least two cores, 14-16 G biopsy needle) or secondary debulking surgery, with tumour samples fixed in methanol (TissueTek Xpress, Sakura Finetek, Torrance, CA, USA) (Piskorz et al, 2016). If 14-16 G cores were felt not to be appropriate (e.g., due to site of disease), three $18 \mathrm{G}$ cores were taken instead. For patients undergoing secondary debulking or other interventional biopsies, $14-16 \mathrm{G}$ cores or a $1 \mathrm{~cm}^{3}$ piece of macroscopically identified tumour tissue were taken. Retrospective registration was allowed only following consultation with the Chief Investigator. All samples were shipped within $24 \mathrm{~h}$ at ambient temperature to the University of Glasgow for processing.

All treatment following study entry was at the discretion of the treating oncologist. Patients optionally also consented to a further biopsy at subsequent progression.

Sample processing, DNA extraction and quantification. A detailed laboratory manual was provided to all study sites. After fixation, tumour samples were processed in a ThermoExcelsior Tissue Processor using optimised protocols (Piskorz et al, 2016). Tumour cellularity was determined on H\&E staining by a pathologist with expertise in gynaecological pathology as the percentage of tumour cells in areas selected for dissection. Up to forty $10 \mu \mathrm{m}$ tissue sections per block were macro- or microdissected. DNA was extracted using QIAmp DNA Micro Kit (Qiagen, Manchester, UK). Quantification was performed by Qubit 2.0 fluorimeter (Life Technologies, Paisley, UK) using dsDNA BR Assay.

Tagged-amplicon sequencing. The coding regions of TP53, PTEN and hotspot regions in EGFR, PIK3CA, KRAS and BRAF were sequenced by tagged-amplicon sequencing (Forshew et al, 2012) on the MiSeq Sequencing System (Illumina, Cambridge, UK) using paired-end $125 \mathrm{bp}$ protocols. Sequencing data analysis was performed as previously (Piskorz et al, 2016).

Statistical analyses. All statistical analyses were performed in Prism for Mac v.6 (GraphPad, La Jolla, CA, USA) and R (v.3.3.2). Adverse event (AE) rates were compared using Pearson's $\chi^{2}$-test, while DNA yields were compared using Wilcoxon rank sum test. All tests were two-sided and $P<0.05$ was considered significant. A complete $\mathrm{R}$ markdown document detailing all analyses is provided as Supplementary Material 8. 


\section{RESULTS}

Patients and recruitment. Recruitment started on 4 January 2013 and involved $14 \mathrm{UK}$ centres. Figure 1 summarises the recruitment and sample numbers. A total of 519 patients were screened (Figure 1A). One hundred and eighty-two patients were ineligible and 117 declined to participate. The most frequent cause of ineligibility was disease deemed not suitable for image-guided biopsy by expert radiologists. Supplementary Material 3 lists all reasons for ineligibility and for declining participation.

Table 1 summarises the clinical characteristics of the 220 enrolled patients, of whom 198 (90\%) were registered prospectively and $22(10 \%)$ retrospectively. The median number of prior chemotherapy lines was 1 (range 1-5) for platinum-sensitive patients and 2 (range 1-12) for platinum-resistant (Supplementary Material 4), and 17 patients $(7.7 \%)$ had received prior bevacizumab. Median overall survival from study entry was 13.4 months for

\section{Table 1. Demographic and disease characteristics}

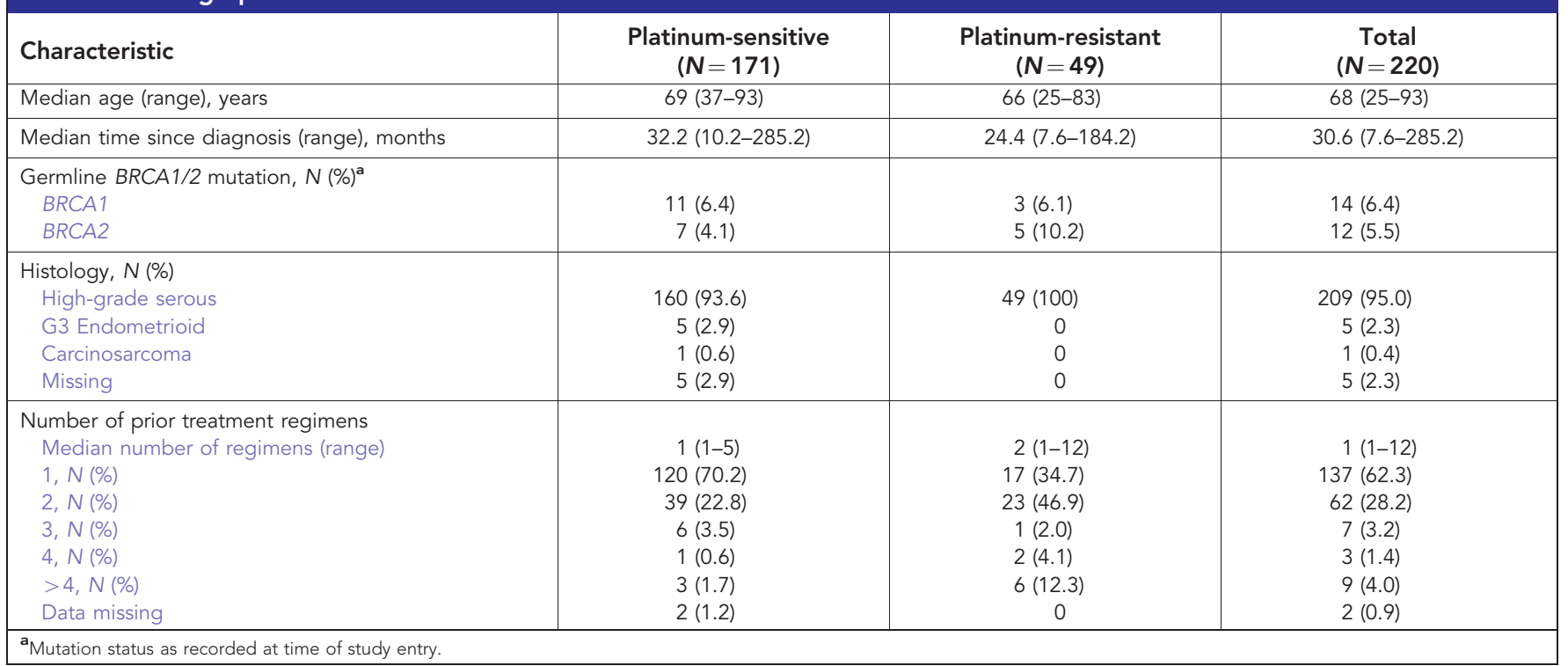

A

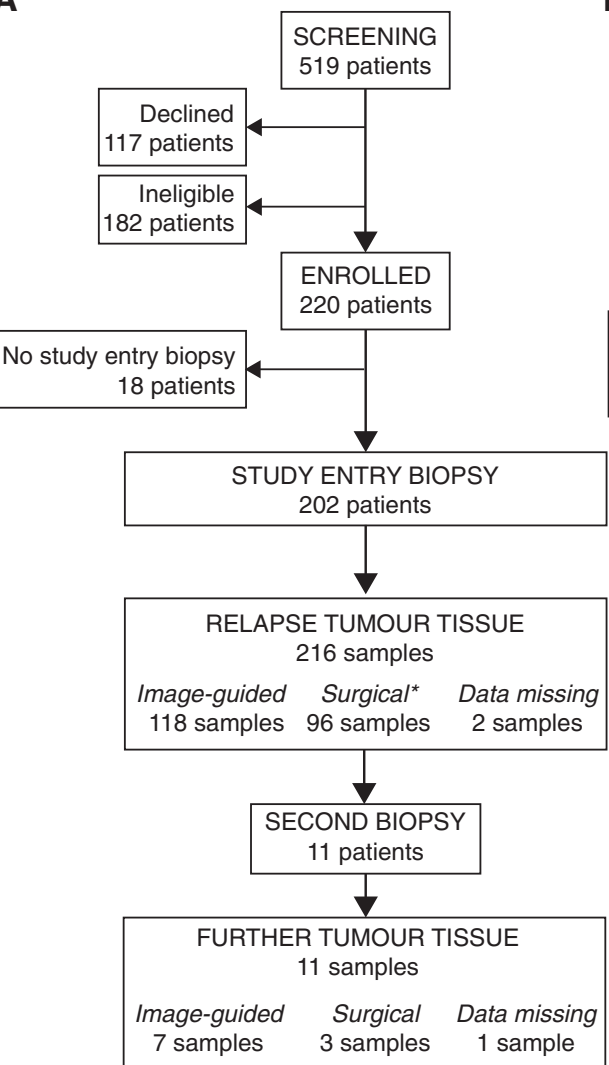

B
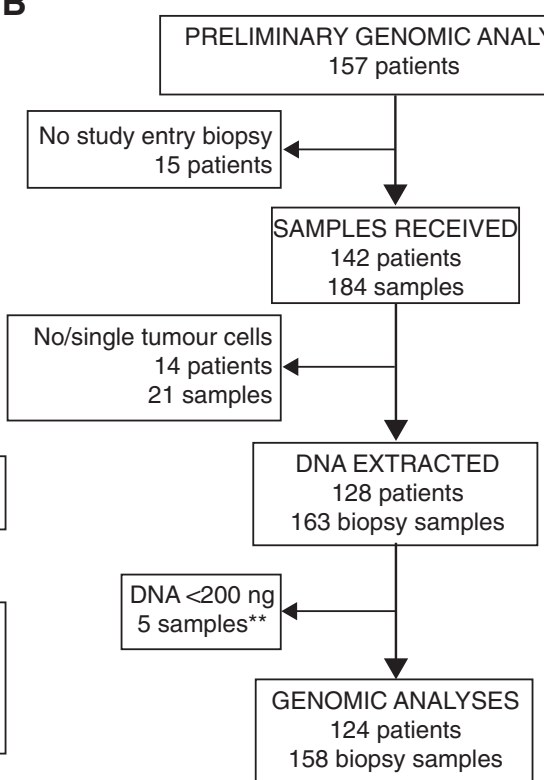

Figure 1. Trial profile. (A) Flow of patients and samples in the BriTROC-1 study. *Patients undergoing other interventional biopsies are classified as 'surgical'. (B) Sample flow from the first 157 patients (B). ${ }^{\star \star}$ Two samples with $<200$ ng DNA were still sufficient for tagged amplicon sequencing analysis. 
Table 2. Biopsy locations by sample

\begin{tabular}{|c|c|c|}
\hline Anatomical location & $\mathbf{N}=$ & $\%$ \\
\hline Lymph node ${ }^{a}$ & 64 & 28.2 \\
\hline Peritoneum & 53 & 23.3 \\
\hline Omentum & 26 & 11.5 \\
\hline Liver & 17 & 7.5 \\
\hline Gynaecological organ ${ }^{\mathbf{b}}$ & 14 & 6.2 \\
\hline Soft tissue (subcutaneous, chest or abdominal wall) & 14 & 6.2 \\
\hline Bowel, serosa or mesentery & 12 & 5.3 \\
\hline Diaphragm & 4 & 1.8 \\
\hline Peri-splenic & 4 & 1.8 \\
\hline Other $^{c}$ & 19 & 8.4 \\
\hline Total & 227 & 100.0 \\
\hline \multicolumn{3}{|c|}{$\begin{array}{l}\text { a Pelvic (14), para-aortic/retroperitoneal (13), other (37). } \\
\text { bVaginal vault (8), uterus, ovary/fallopian tube (6). } \\
\text { c }_{\text {Bladder wall (3), brain (2), iliac fossa (2), pelvic/pelvic sidewall (2), breast (1), paracolic gutter }} \\
\text { (1), para-sternal (1), perinephric (1), pleural (1), retro-caecal (1), small bowel (1), trachea (1), } \\
\text { lung (1), obturator fossa (1). }\end{array}$} \\
\hline
\end{tabular}

the platinum-resistant patients and 34.9 months for platinumsensitive patients (Glasgow and Edinburgh patients, $n=68$; Supplementary Material 5).

Biopsies. Eighteen of the 220 (8.2\%) consented patients did not complete study-entry biopsy, most commonly because disease was found to be unsuitable for biopsy during the procedure. Therefore, 202 patients completed study-entry biopsy procedure, including 118 image-guided biopsies, yielding a total of 216 relapse tumour samples. Eleven patients also underwent a second biopsy procedure (seven image-guided) upon subsequent progression, including one patient whose study entry biopsy had been unsuccessful. Thus, a total of 227 tumour samples were collected. Reflecting the pattern of spread of HGSC, these samples were obtained from multiple different anatomical locations (Table 2). The commonest sites were lymph node (64 samples), peritoneum (53 samples), omentum (26 samples) and liver (17 samples). Out of the 125 image-guided biopsy procedures (118 at study entry, 7 at second biopsy), needle size information was available for 120: 17/120 (14.2\%) used $14 \mathrm{G}$ needles, 49 (40.8\%) $16 \mathrm{G}$ and 54 (45.0\%) $18 \mathrm{G}$.

Study-related AEs were recorded for image-guided biopsy procedures (A full listing is given in Supplementary Material 6). Twenty-two AEs of any grade were reported (20 baseline biopsy, 2 second biopsy) in 18/125 (14.4\%) procedures (Table 3). Pain was the commonest $\operatorname{AE~}(16 / 22,72.7 \% ; 13$ grade 1,3 grade 2$)$. The frequency of AEs was not significantly higher for $14 \mathrm{G}$ (five events in 17 biopsies) or $16 \mathrm{G}(6 / 49)$ needles compared to $18 \mathrm{G}(11 / 54$; $P=0.228)$. Pre-specified significant complications were reported in $3 / 125$ (2.4\%) biopsies; two for grade 2 pain and one for combined grade 2 pain and grade 2 haemorrhage (liver haematoma). The grade 2 haemorrhage was managed conservatively and did not require transfusion or any active intervention. There was only one other grade $2 \mathrm{AE}$, of vaginal discharge in one patient, which was also managed conservatively. CUSUM control boundaries were not crossed and all complications resolved without long-term sequelae.

Quality of biopsies. We analysed samples from the first 157 patients, of whom 15 did not successfully complete study-entry biopsy. The remaining 142 patients yielded 184 samples (Figure 1B). At pathology review, 21/184 (11.4\%) samples from 14 patients were found to contain no or few tumour cells, leaving 163 tumour samples (88 from image-guided biopsies, 75 from surgical). Following dissection (41 macrodissection, 122 microdissection), median tumour cellularity was 65\% (IQR 45\%-75\%). The median DNA yield was $2.87 \mu \mathrm{g}$ (IQR 0.78-8.19). Five samples
Table 3. Adverse events in 125 image-guided biopsy procedures

\begin{tabular}{|c|c|c|}
\hline Event type $^{a}$ & Grade 1 & Grade 2 \\
\hline Pain & 13 & 3 \\
\hline Haemorrhage & 3 & 1 \\
\hline Vaginal discharge & 0 & 1 \\
\hline Other $^{\mathbf{b}}$ & 1 & 0 \\
\hline \multicolumn{3}{|c|}{$\begin{array}{l}\text { ane biopsy could have }>1 \text { adverse events. These events were reported from } 19 \text { biopsy } \\
\text { procedures in } 18 \text { patients. } \\
\text { b }_{\text {Haematoma. }}\end{array}$} \\
\hline
\end{tabular}

(3.1\%) yielded $<200 \mathrm{ng}$ DNA, the minimum pre-specified for genomic analyses, although 2 of these 5 were still sufficient for tagged amplicon sequencing. For image-guided biopsies (Figure 2A), median DNA yield was $1.96 \mu \mathrm{g}$ (IQR 0.62-3.39), whilst surgical sample median was significantly higher $(4.64 \mu \mathrm{g}$ (IQR 1.96-10.14); $P<<0.001$ ). In image-guided biopsies (Figure 2B), median yield was significantly higher for $14 \mathrm{G} / 16 \mathrm{G}$ needles $(2.86 \mu \mathrm{g}$ [IQR $0.85-5.54$ ]) than for $18 \mathrm{G}(0.89 \mu \mathrm{g}$ (IQR $0.47-2.92), P=0.011)$.

By anatomical location in image-guided biopsies specifically (Figure 2C), the highest median DNA yields were obtained from gynaecological organs $(8.82 \mu \mathrm{g}$ (IQR 3.16-13.36 $\mu \mathrm{g})$ ), peritoneum $(2.86 \mu \mathrm{g}$ (IQR 0.62-4.56)) and lymph nodes $(2.32 \mu \mathrm{g}$ (IQR $0.63-$ 3.18)), although these differences did not reach statistical significance. There was a significant correlation (Spearman $\rho=0.304, P<<0.001$ ) between tumour cellularity and overall DNA yield (Figure 2D)

Using tagged amplicon next-generation sequencing (median read depth $1086 \times)$, TP53 mutations were identified in $94.4 \%(118 / 125)$ patients (Figure 3A) with mean mutant allele frequency (MAF) 0.55 . These included 71 (60.2\%) nonsynonymous (missense), 41 (34.7\%) loss of function mutations (nonsense, splicing and frameshift) and $6(5.1 \%)$ inframe indels. Mutations in KRAS, PIK3CA and PTEN were identified in $4.8 \%(6 / 125), 2.4 \%$ (3/125) and $1.6 \%$ (2/125) patients respectively. No mutations were detected in EGFR or $B R A F$. Overall, we found a strong correlation between cellularity and TP53 MAF (Figure 3B, Spearman $\rho=0.314, P<<0.001$ ) and a weaker, but still significant, correlation between DNA yield and TP53 MAF $(\rho=0.220, P=0.0034)$.

\section{DISCUSSION}

In this study, we demonstrate that obtaining tumour biopsies in women with relapsed ovarian cancer is feasible and safe, and can be co-ordinated across multiple academic centres. Moreover, we demonstrate that patients with recurrent ovarian cancer are willing to undergo a research biopsy for purely altruistic purposes; treatment following the biopsy was at the local investigator's discretion and there was no investigational agent on offer.

In order to recruit 220 patients, we had to screen 519-the commonest reason for non-participation was disease thought not to be amenable to image-guided biopsy on review of imaging. Thus, our image-guided biopsies were obtained from women with relatively bulky disease. However, median OS (13.4 months and 34.9 months, respectively, for platinum-resistant and platinumsensitive patients) was comparable to that in the control arms of recent large randomised studies (Aghajanian et al, 2012; Pujade-Lauraine et al, 2014), and tagged amplicon sequencing demonstrated near-universal TP53 mutation and low-frequency mutations in KRAS, PIK3CA and PTEN, in keeping with previous data in HGSC (Ahmed et al, 2010; TCGA, 2011; Köbel et al, 2016). Thus, we believe that our patients are similar to other trial 
A

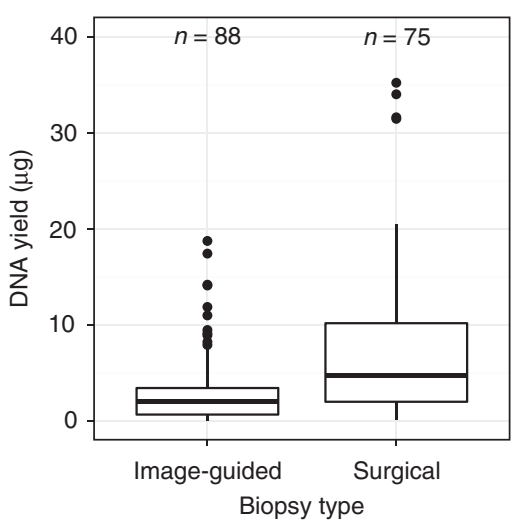

C

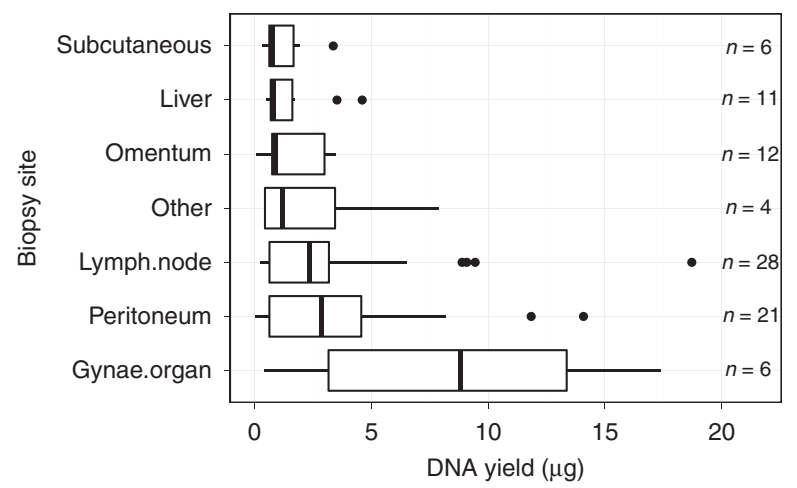

B

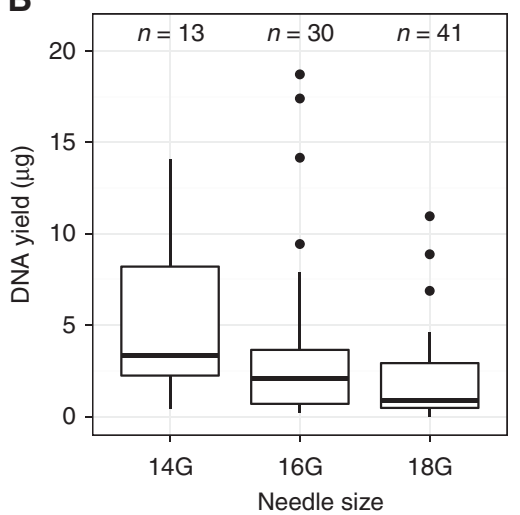

D

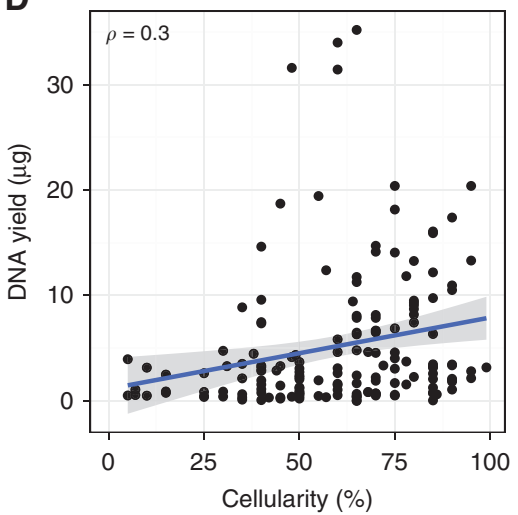

Figure 2. DNA yields. (A) DNA yield in image-guided and surgical biopsies. ${ }^{\star \star \star \star} P<0.0001$. (B) DNA yield was significantly greater in imageguided biopsies using $14 \mathrm{G}$ or $16 \mathrm{G}$ needles compared to $18 \mathrm{G}$. ${ }^{\star \star} P=0.0022$. (C) DNA yields according to anatomical site of biopsy for image-guided procedures. (D) Correlation between DNA yield and tumour cellularity. Number represents Spearman rank correlation coefficient $\rho$. $P<<0.001$. Line represents linear regression $\pm 95 \% \mathrm{Cl}$.

populations in relapsed ovarian cancer. Seven patients were found to have TP53 wild-type tumours, three of which harboured KRAS mutations. Two of these cases were diagnosed before the binary grading of serous carcinomas was introduced and had been originally classified as 'grade 2 serous' tumours. In other cases, the reporting pathologists stated that grading was difficult or that there were areas of borderline change. Thus, it is likely that these cases represent low-grade serous carcinomas that were misclassified at the time of original diagnosis.

Adverse events were generally rare, with grade 1 pain as the commonest event following image-guided biopsy, recorded in 13 cases. There were only three expedited AEs, a figure comparable to results reported from large single centre series (El-Osta et al, 2011; Gomez-Roca et al, 2012), and one other grade $2 \mathrm{AE}$ (vaginal discharge), in one patient. However, it is clearly important that patients are properly consented before research biopsy procedures, and these data provide robust safety information to inform the consent process in patients with relapsed ovarian cancer in future.

We fixed samples in a methanol-based fixative that we have previously shown to be superior to buffered formalin for genomic studies (Piskorz et al, 2016). In addition, methanol fixation allows samples to be transported and stored at ambient temperature and analysed by IHC, both distinct advantages over snap-frozen samples for a multi-centre study. We highlight that, although $11.4 \%(21 / 184)$ samples contained $<20 \%$ tumour cells, only three of the remaining 164 samples yielded no usable DNA. Thus, overall $87 \%$ of the biopsies were fit-for-purpose. These figures are comparable to the ARIEL2 study, which investigated genomic LOH as a potential predictive biomarker of response to the PARP inhibitor rucaparib (Swisher et al, 2017). In ARIEL2, 136/152
(89.5\%) relapse biopsies yielded sufficient DNA for LOH analyses. Three of the samples in our study with $<200 \mathrm{ng}$ yields utilised an $18 \mathrm{G}$ needle-our results show that $14 \mathrm{G} / 16 \mathrm{G}$ needles generate higher DNA yields but do not cause more frequent AEs. We thus recommend the use of larger gauge needles for biopsies where genomic analyses are planned.

In terms of anatomical biopsy location, experience from the MOSCATO-01 study indicated that bone biopsies were associated with the lowest rates of tumour cellularity (Tacher et al, 2016). In our series, there were no bone biopsies, given the pattern of dissemination of HGSC. The commonest site of biopsy was lymph node-the choice of biopsy site was at the discretion of the radiologist undertaking the procedure for image-guided biopsies. Thus, these were the most accessible sites in the participating patients rather than the only sites of relapse. We found that biopsies from gynaecological organs yielded the highest quantities of DNA in image-guided procedures, although the differences between biopsy sites were not significant. We found strong correlation between tumour cellularity and TP53 mutant allele fraction, as well as correlation between DNA yield and cellularity. The correlation between total DNA yield and mutant allele fraction was still significant, although more weakly than the other two analyses. This suggests that, although DNA yield is important, dissection of samples to ensure high tumour cellularity is critical when processing biopsies for genomic studies.

The scientific purpose of the BriTROC programme will be to investigate changes in cancer biology as tumours recur and develop chemotherapy resistance. Intra-tumoural spatial heterogeneity is a potential concern when examining single core biopsies in patients with multi-site relapse, and the recent International Cancer Genome Consortium analysis identified multiple separate 
A

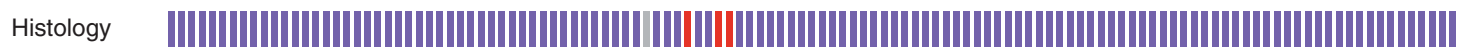

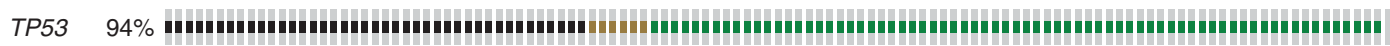

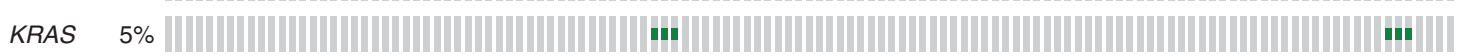

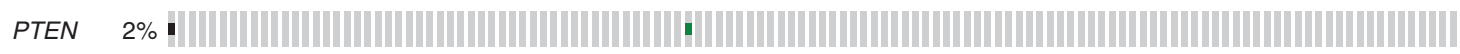

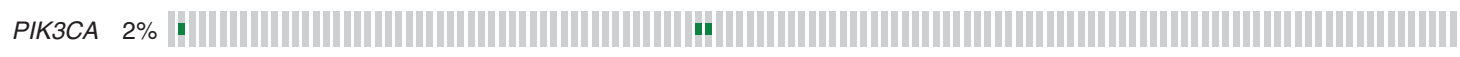
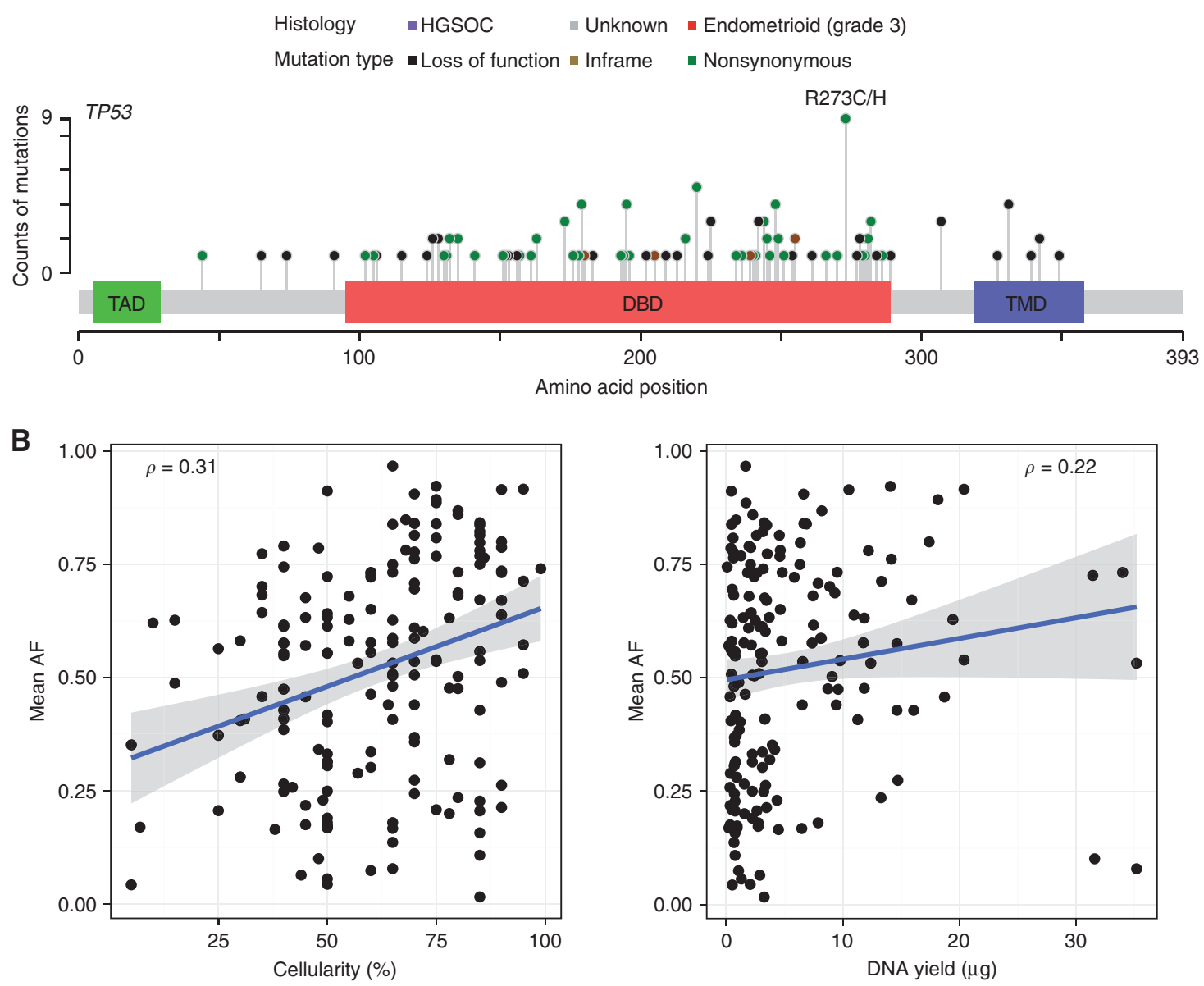

Figure 3. Mutation analysis. (A) Mutations in TP53, KRAS, PIK3CA and PTEN identified in 125 patients by tagged amplicon sequencing with histological subtype (upper). No mutations in EGFR or BRAF were identified in any sample (Cerami et al, 2012; Gao et al, 2013). Schematic representation of p53 (lower) showing protein domains (Green, transactivation domain; red, DNA binding domain; blue, tetramerisation domain) with lollipops showing positions and counts of identified mutations. Mutation type is indicated by circle fill: black, loss of function (including nonsense, splicing and frameshift); brown, inframe indels; green, nonsynonymous. (B) Correlation between cellularity in dissected areas and TP53 mutant allele fraction (MAF)—left, $(P<<0.001)$, and between DNA yield and TP53 mutant allele fraction-right, $(P=0.0034)$. Numbers represent Spearman rank correlation coefficient $\rho$. Lines represent linear regression $\pm 95 \% \mathrm{Cl}$.

reversion events in post-mortem analysis of a germline BRCA2 mutation carrier with HGSC (Patch et al, 2015). We have allowed patients undergoing secondary debulking surgery to enter BriTROC-1, and five of these patients have donated multiple samples.

In early phase trials, there is evidence that patients are broadly willing to undergo translational biopsies (Seah et al, 2013), although rates of take-up are highest for mandatory biopsies (ElOsta et al, 2011). Scheduling research biopsies in busy interventional radiology departments can be challenging-we demonstrate here that it is logistically possibly to do so, and centres received a standard per-biopsy fee of $£ 800$ (approximately US\$1000, €950) to cover the cost of the scan (CT or ultrasound), the radiologist's time, the biopsy needle and fixative. There is variation in the reporting of research biopsies (Freeman et al, 2013), and we believe that it is essential that biomarker biopsy studies are reported consistently to improve future trials. Such reports should include complete details for biopsy sites, the number of biopsies, the protocol for tissue analysis and overall outcome. BriTROC- 1 shows that research biopsies that are fit-for-purpose for genomic analyses can be readily and safely obtained from women with recurrent HGSC across multiple centres. Although the yields from surgical biopsies were higher, image-guided biopsies are satisfactory, less invasive and obviate the need for a general anaesthetic in patients not scheduled for secondary debulking surgery. From these results, we recommend the use of methanol fixation and of $14 \mathrm{G}$ or $16 \mathrm{G}$ needles for biopsies as they are associated with optimum DNA yield but no increase in AEs.

\section{ACKNOWLEDGEMENTS}

We acknowledge our patients and their caregivers, and the help and support of the research nurses, trial staff and the staff at all the 
BriTROC centres. We thank Aishah Hanif for assistance with collating patient data, and the Translational Pharmacology Laboratory, University of Glasgow for registration of all in-coming samples. We thank the University of Cambridge, Cancer Research UK, and Hutchison Whampoa. The Human Research Tissue Bank is supported by the NIHR Cambridge Biomedical Research Centre. We thank the Biorepository, Bioinformatics, Histopathology and Genomics Core Facilities of the Cancer Research UK Cambridge Institute for technical support. The BriTROC-1 study was funded by Ovarian Cancer Action (to IMcN and JDB, grant number 006) and supported by Cancer Research UK (grant numbers A15973, A15601, A18072), the Universities of Cambridge and Glasgow, National Institute for Health Research Cambridge Biomedical Research Centre, National Cancer Research Network, the Experimental Cancer Medicine Centres at participating sites, and Hutchison Whampoa Limited. The funders had no role in study design, data collection and analysis, decision to publish or preparation of the manuscript.

\section{CONFLICT OF INTEREST}

The authors declare no conflict of interest.

\section{AUTHOR CONTRIBUTIONS}

Study design: IMcN, JDB, JP, TG, AP, DE and GM. Patient recruitment: IMcN, JDB, RMG, DK, ML, EB, AM, AW, SS, RE, GH, AC, CG, MH, SF, CF and HG. Pathological assessment: LM and MJL. Data acquisition: LAL, JS, CW, TG, AP, DE, GM and IMcN. Data analysis: JS, TG, DE, AP, GM, JP, IMcN and JDB. Manuscript preparation: IMcN, JDB, TG, DE and AP. All authors reviewed the manuscript before submission.

\section{REFERENCES}

Aghajanian C, Blank SV, Goff BA, Judson PL, Teneriello MG, Husain A, Sovak MA, Yi J, Nycum LR (2012) OCEANS: a randomized, double-blind, placebo-controlled phase III trial of chemotherapy with or without bevacizumab in patients with platinum-sensitive recurrent epithelial ovarian, primary peritoneal, or fallopian tube cancer. J Clin Oncol 30(17): 2039-2045.

Ahmed AA, Etemadmoghadam D, Temple J, Lynch AG, Riad M, Sharma R, Stewart C, Fereday S, Caldas C, Defazio A, Bowtell D, Brenton JD (2010) Driver mutations in TP53 are ubiquitous in high grade serous carcinoma of the ovary. J Pathol 221(1): 49-56.

Cerami E, Gao J, Dogrusoz U, Gross BE, Sumer SO, Aksoy BA, Jacobsen A, Byrne CJ, Heuer ML, Larsson E, Antipin Y, Reva B, Goldberg AP, Sander C, Schultz N (2012) The cBio cancer genomics portal: an open platform for exploring multidimensional cancer genomics data. Cancer Discov 2(5): 401-404.

Edwards SL, Brough R, Lord CJ, Natrajan R, Vatcheva R, Levine DA, Boyd J, Reis-Filho JS, Ashworth A (2008) Resistance to therapy caused by intragenic deletion in BRCA2. Nature 451(7182): 1111-1115.

El-Osta H, Hong D, Wheler J, Fu S, Naing A, Falchook G, Hicks M, Wen S, Tsimberidou AM, Kurzrock R (2011) Outcomes of research biopsies in phase I clinical trials: the MD anderson cancer center experience. Oncologist 16(9): 1292-1298.

Forshew T, Murtaza M, Parkinson C, Gale D, Tsui DW, Kaper F, Dawson SJ, Piskorz AM, Jimenez-Linan M, Bentley D, Hadfield J, May AP, Caldas C, Brenton JD, Rosenfeld N (2012) Noninvasive identification and monitoring of cancer mutations by targeted deep sequencing of plasma DNA. Sci Transl Med 4(136): 136ra68.

Freeman GA, Kimmelman J, Dancey J, Monzon JG (2013) Reporting practices of pharmacodynamic studies involving invasive research procedures in cancer trials. Br J Cancer 109(4): 897-908.
Gao J, Aksoy BA, Dogrusoz U, Dresdner G, Gross B, Sumer SO, Sun Y, Jacobsen A, Sinha R, Larsson E, Cerami E, Sander C, Schultz N (2013) Integrative analysis of complex cancer genomics and clinical profiles using the cBioPortal. Sci Signal 6(269): pl1.

Gomez-Roca CA, Lacroix L, Massard C, De Baere T, Deschamps F, Pramod R, Bahleda R, Deutsch E, Bourgier C, Angevin E, Lazar V, Ribrag V, Koscielny S, Chami L, Lassau N, Dromain C, Robert C, Routier E, Armand JP, Soria JC (2012) Sequential research-related biopsies in phase I trials: acceptance, feasibility and safety. Ann Oncol 23(5): 1301-1306.

Gorringe KL, George J, Anglesio MS, Ramakrishna M, Etemadmoghadam D, Cowin P, Sridhar A, Williams LH, Boyle SE, Yanaihara N, Okamoto A, Urashima M, Smyth GK, Campbell IG, Bowtell DD. Australian Ovarian Cancer S (2010) Copy number analysis identifies novel interactions between genomic loci in ovarian cancer. PLoS One 5(9): pii: el1408.

Griffin N, Grant LA, Freeman SJ, Jimenez-Linan M, Berman LH, Earl H, Ahmed AA, Crawford R, Brenton J, Sala E (2009) Image-guided biopsy in patients with suspected ovarian carcinoma: a safe and effective technique? Eur Radiol 19(1): 230-235.

Köbel M, Piskorz AM, Lee S, Lui S, LePage C, Marass F, Rosenfeld N, Mes Masson A-M, Brenton JD (2016) Optimized p53 immunohistochemistry is an accurate predictor of TP53 mutation in ovarian carcinoma. J Pathol Clin Res 2: 247-258.

Lerch L, Donald JC, Olivotto IA, Lesperance M, van der Westhuizen N, Rusnak C, Biberdorf D, Ross A, Hayashi A (2007) Measuring surgeon performance of sentinel lymph node biopsy in breast cancer treatment by cumulative sum analysis. Am J Surg 193(5): 556-559.

Mackay HJ, Brady MF, Oza AM, Reuss A, Pujade-Lauraine E, Swart AM, Siddiqui N, Colombo N, Bookman MA, Pfisterer J, du Bois A (2010) Prognostic relevance of uncommon ovarian histology in women with stage III/IV epithelial ovarian cancer. Int J Gynecol Cancer 20(6): 945-952.

Oza AM, Cook AD, Pfisterer J, Embleton A, Ledermann JA, Pujade-Lauraine E, Kristensen G, Carey MS, Beale P, Cervantes A, Park-Simon T-W, Rustin G, Joly F, Mirza MR, Plante M, Quinn M, Poveda A, Jayson GC, Stark D, Swart AM, Farrelly L, Kaplan R, Parmar MKB, Perren TJ. investigators It (2015) Standard chemotherapy with or without bevacizumab for women with newly diagnosed ovarian cancer (ICON7): overall survival results of a phase 3 randomised trial. Lancet Oncol 16(8): 928-936.

Patch A-M, Christie EL, Etemadmoghadam D, Garsed DW, George J, Fereday S, Nones K, Cowin P, Alsop K, Bailey PJ, Kassahn KS, Newell F, Quinn MCJ, Kazakoff S, Quek K, Wilhelm-Benartzi C, Curry E, Leong HS. The Australian Ovarian Cancer Study GHamilton A, Mileshkin L, Au-Yeung G, Kennedy C, Hung J, Chiew Y-E, Harnett P, Friedlander M, Quinn M, Pyman J, Cordner S, O/'Brien P, Leditschke J, Young G, Strachan K, Waring P, Azar W, Mitchell C, Traficante N, Hendley J, Thorne H, Shackleton M, Miller DK, Arnau GM, Tothill RW, Holloway TP, Semple T, Harliwong I, Nourse C, Nourbakhsh E, Manning S, Idrisoglu S, Bruxner TJC, Christ AN, Poudel B, Holmes O, Anderson M, Leonard C, Lonie A, Hall N, Wood S, Taylor DF, Xu Q, Fink JL, Waddell N, Drapkin R, Stronach E, Gabra H, Brown R, Jewell A, Nagaraj SH, Markham E, Wilson PJ, Ellul J, McNally O, Doyle MA, Vedururu R, Stewart C, Lengyel E, Pearson JV, Waddell N, deFazio A, Grimmond SM, Bowtell DDL (2015) Whole-genome characterization of chemoresistant ovarian cancer. Nature 521(7553): 489-494.

Piskorz AM, Ennis D, Macintyre G, Goranova TE, Eldridge M, Segui-Gracia N, Valganon M, Hoyle A, Orange C, Moore L, Jimenez-Linan M, Millan D, McNeish IA, Brenton JD (2016) Methanol-based fixation is superior to buffered formalin for next-generation sequencing of DNA from clinical cancer samples. Ann Oncol 27(3): 532-539.

Pujade-Lauraine E, Hilpert F, Weber B, Reuss A, Poveda A, Kristensen G, Sorio R, Vergote I, Witteveen P, Bamias A, Pereira D, Wimberger P, Oaknin A, Mirza MR, Follana P, Bollag D, Ray-Coquard I (2014) Bevacizumab combined with chemotherapy for platinum-resistant recurrent ovarian cancer: The AURELIA Open-Label Randomized Phase III Trial. J Clin Oncol 32(13): 1302-1308.

Sakai W, Swisher EM, Karlan BY, Agarwal MK, Higgins J, Friedman C, Villegas E, Jacquemont C, Farrugia DJ, Couch FJ, Urban N, Taniguchi T (2008) Secondary mutations as a mechanism of cisplatin resistance in BRCA2-mutated cancers. Nature 451(7182): 1116-1120.

Schwarz RF, Ng CK, Cooke SL, Newman S, Temple J, Piskorz AM, Gale D, Sayal K, Murtaza M, Baldwin PJ, Rosenfeld N, Earl HM, Sala E, 
Jimenez-Linan M, Parkinson CA, Markowetz F, Brenton JD (2015) Spatial and temporal heterogeneity in high-grade serous ovarian cancer: a phylogenetic analysis. PLoS Med 12(2): e1001789.

Seah DS, Scott SM, Najita J, Openshaw T, Krag K, Frank E, Sohl J, Stadler ZK, Garrett M, Silverman SG, Peppercorn J, Winer EP, Come SE, Lin NU (2013) Attitudes of patients with metastatic breast cancer toward research biopsies. Ann Oncol 24(7): 1853-1859.

Spencer JA, Anderson K, Weston M, Wilkinson N, Hewitt M (2006) Image guided biopsy in the management of cancer of the ovary. Cancer Imaging 6: 144-147.

Swisher EM, Lin KK, Oza AM, Scott CL, Giordano H, Sun J, Konecny GE, Coleman RL, Tinker AV, O’Malley DM, Kristeleit RS, Ma L, Bell-McGuinn KM, Brenton JD, Cragun JM, Oaknin A, Ray-Coquard I, Harrell MI, Mann E, Kaufmann SH, Floquet A, Leary A, Harding TC, Goble S, Maloney L, Isaacson J, Allen AR, Rolfe L, Yelensky R, Raponi M, McNeish IA (2017) Rucaparib in relapsed, platinum-sensitive high-grade ovarian carcinoma (ARIEL2 Part 1): an international, multicentre, open-label, phase 2 trial. Lancet Oncol 18(1): 75-87.
Tacher V, Le Deley MC, Hollebecque A, Deschamps F, Vielh P, Hakime A, Ileana E, Abedi-Ardekani B, Charpy C, Massard C, Rosellini S, Gajda D, Celebic A, Ferte C, Ngo-Camus M, Gouissem S, Koubi-Pick V, Andre F, Vassal G, Deandreis D, Lacroix L, Soria JC, De Baere T (2016) Factors associated with success of image-guided tumour biopsies: results from a prospective molecular triage study (MOSCATO-01). Eur J Cancer 59: 79-89.

TCGA (2011) Integrated genomic analyses of ovarian carcinoma. Nature 474(7353): 609-615.

(1)(2) This work is licensed under the Creative Commons Attribution-Non-Commercial-Share Alike 4.0 International License. To view a copy of this license, visit http:// creativecommons.org/licenses/by-nc-sa/4.0/

(C) The Author(s) named above 2017

Supplementary Information accompanies this paper on British Journal of Cancer website (http://www.nature.com/bjc) 